\title{
INOVAÇÃO E APRENDIZAGEM ATIVA NA EDUCAÇÃO SUPERIOR NA MODALIDADE A DISTÂNCIA
}

\author{
MARINGÁ/PR JUNHO/2018
}

\author{
MARCIA MARIA PREVIATO DE SOUZA - Unicesumar - marcia.previato@unicesumar.edu.br \\ HELAINE PATRICIA FERREIRA - Unicesumar - helaine.ferreira@unicesumar.edu.br \\ CAMILA TECLA MORTEAN - Unicesumar - camila.mortean@unicesumar.edu.br \\ SONIA MARIA DE CAMPOS SILVA - Unicesumar - sonia.silva@unicesumar.edu.br
}

Tipo: Investigação Científica (IC)

Natureza: Relatório Final de Pesquisa

Categoria: Métodos e Tecnologias

Setor Educacional: EDUCAÇÃO SUPERIOR

\begin{abstract}
RESUMO
O maior desafio que a educação encontra é de auxiliar na formação de indivíduos críticos, que saibam interagir e resolver problemas em equipe, capazes de ter opiniões e defende-las de maneira responsável. Diante disso, o presente estudo visa compreender o Problem Based-Learning (PBL) que significa Aprendizagem Baseada em Problemas como ferramenta das metodologias ativas em propiciar conhecimento auto dirigido, centrado no aluno por meio de grupos de estudantes. Para tanto, é feito uma análise em relação ao PBL como ferramenta no auxílio na construção de conhecimentos no aluno da Educação a distância (EaD). Para isso, é feito uma observação em um curso de Pedagogia na modalidade a Distância, bem como se pautando em um embasamento bibliográfico relevante. Os resultados alcançados mostram que a PBL pode auxiliar o aluno em ser disciplinado com seus estudos, e ter iniciativa para estudar por conta própria, como também é possível desenvolver o aprendizado de maneira flexível, por meio de leitura e discussão em grupo, eficaz no processo de aprendizagem ativa.
\end{abstract}

Palavras-chave: Educação à distância. Aprendizagem ativa. PBL.

\section{AGRADECIMENTOS}

AGRADECEMOS A UNICESUMAR POR TER DISPONIBILIZADO O ESPAÇO PARA EFETUAR A PESQUISA. 


\section{INTRODUÇÃo}

A Aprendizagem Baseada em Problema é um novo caminho das metodologias ativas na Educação a Distância, a PBL faz parte das metodologias educacionais inovadoras com o objetivo de estimular o aluno ao pensamento crítico, levando-o a desenvolver várias habilidades ao mesmo tempo, chegando à solução dos problemas por meio de conhecimentos e conceitos fundamentados pelo seu curso. Ao contrário do modelo convencional a PBL, usa o problema para estimular, prender e iniciar a aprendizagem. Além de promover a construção dos conhecimentos, objetiva também o desenvolvimento de habilidades e comportamentos importantes para uma prática profissional promissora.

A presente pesquisa é de natureza qualitativa, que visa compreender o processo de ensinar e como aprender por meio da PBL oferecida no curso de Pedagogia EaD. Para isso, é feito uma análise na maneira de implementação de uma metodologia de aprendizagem ativa como ferramenta e estratégia pedagógica, buscando construir o conhecimento de forma colaborativa.

No primeiro momento é feito a caracterização histórica da PBL, os princípios de implementação, e sua aplicação, para que assim o estudo leve a uma compreensão do leitor da importância da aprendizagem baseada em problematização tornando-a significativa.

Entende-se a necessidade desta pesquisa para a sociedade, não sendo conclusiva, mas provocativa, em relação ao desenvolvimento dos processos de ensinar e aprender na EaD por meio da PBL. Esse fato facilita uma conclusão por meio dos dados copilados e embasados.

\section{APRENDIZAGEM BASEADA EM PROBLEMAS NA EDUCAÇÃO A DISTÂNCIA}

A aprendizagem baseada em problemas - PBL que em Inglês significa (Problem Based Learning) consiste em um método de aprendizagem que tem ganhado espaço dentro das instituições de ensino básico e superior no decorrer das últimas décadas. A PBL surge com o objetivo de utilizar da inovação para tornar uma estratégia, que visa ressaltar a capacidade de aprender e aplicar os conhecimentos na solução de problemas partindo de um contexto significativo do meio do estudante (SOUZA; DOURADO, 2015). 
a compreensão e resolução de problemas de forma significativa e em interação contínua com o professor tutor (SOUZA; DOURADO, 2015, p. 184-185).

Para Souza e Dourado (2015) o método PBL trabalha o processo de ensino e aprendizagem apresentando os problemas como ponto de partida, a fim de que os alunos possam construir e interagir com os novos conhecimentos. Em tese, o centro do processo de ensino e aprendizagem é o aluno. O professor por sua vez, assume o papel de mediador, ou seja, ele é o facilitador do processo de construção do conhecimento. Neste contexto, os problemas que são apresentados funcionam como estímulo no processo de ensino e aprendizagem e no desenvolvimento das habilidades de resolução de problemas.

Desta forma, Souza e Dourado (2015, p. 187) completam que:

O foco na problematização possibilita uma visão transdisciplinar e tem como ponto de partida o levantamento de questões e a busca de soluções para os problemas identificados nos temas curriculares de cada disciplina, nos respectivos níveis de aprendizagem, com a finalidade de produzir conhecimento.

É sabido que uma das características do ser humano está ligada a curiosidade e a criatividade. E ao utilizar as metodologias ativas e, principalmente, a PBL, a Instituição de ensino dá a oportunidade do aluno se sentir valorizado dentro do que já é natural nele, incentivando-o a utilizar esses instintos de curiosidade e criatividade em favor da aprendizagem. Pois o objetivo da PBL é incentivar o aluno aprender a aprender, buscando a independência e construindo o seu meio de aproveitar suas capacidades em toda a sua vida.

O método possui como um dos principais pilares ensinar o aluno a aprender, conduzindoo na busca e construção do conhecimento, por meio das tecnologias digitais da informação e da comunicação (SOUZA; DOURADO, 2015).

Mas para que o ensino e aprendizagem ocorram, espera-se-que: os alunos tenham esclarecido os termos e conceitos desconhecidos, reconhecido o problema, para isso, o aluno realizará a análise do problema baseado em conhecimentos prévios, chegando a uma conclusão dos fatos, traçar uma formula ou metas de estudo, que poderão proporcionar a autoaprendizagem, compartilhando conhecimentos com o grupo. Pois a proposta de trabalhar com a metodologia PBL é para os alunos que possuem iniciativa em estudar do seu jeito, de forma flexível e assim, desenvolve sua formação crítica.

Para Park (2006, p. 21) destaca o PBL "Sendo uma atividade trabalhada de forma autodirigida, em que o estudante é o foco. Os alunos levantam suas dúvidas diante de 
suas dificuldades de compreensão e o professor direciona e facilita quando necessário e apresenta novas formas e recursos para cada situação" $O$ autos ainda menciona que na educacional o PBL possui cinco características principais "Um problema mal definido; construção do conhecimento em volta do problema; o papel do professor como facilitador; domínio do estudante; e cooperação por meio de atividade de grupo".

Neste processo de construção de novos conhecimentos, é que se percebe a eficácia que a PBL traz, ao promover uma integração entre a teoria e a prática, levando assim a uma maior retenção do conhecimento por parte dos indivíduos. Mas para que ocorra uma real participação de todos, é relevante destacar e definir uma situação-problema que leve ao interesse dos alunos em buscar a solução. Conforme afirma Dewey (1979, p. 179),

\footnotetext{
Os pontos essenciais do método coincidem com os pontos essenciais da reflexão. Primeiro, que o aluno esteja em uma verdadeira situação de experiência; que haja uma atividade contínua a interessá-lo. Segundo, que um verdadeiro problema se desenvolva nesta situação como um estímulo para o ato de pensar. Terceiro, que ele possua os conhecimentos informativos necessários para agir nessa situação e faça as observações necessárias para o mesmo fim. Quarto, que ocorram sugestões para a solução e que fique a cargo dele desenvolvê-las de modo bem ordenado. Quinto, que tenha oportunidades para por em prova suas ideias, aplicando-as, tornando-Ihes clara a significação e descobrindo por si próprio o valor delas.
}

A aprendizagem baseada em problemas foi pensada de forma que os alunos consigam desenvolver as suas capacidades e habilidades para realizar investigações de forma metódica e sistemática, de forma a oferecer aos alunos um aprendizado também na forma de trabalhar em grupo, a fim de alcançar os seus objetivos de forma satisfatória, complementando assim o aprendizado individual.

E na EaD, sendo esta definida nos documentos oficiais como:

Modalidade educacional na qual a mediação didático-pedagógica nos processos de ensino e aprendizagem ocorre com a utilização de meios e tecnologias de informação e comunicação, com estudantes e professores desenvolvendo atividades educativas em lugares ou tempos diversos. (BRASIL, 2005).

Analisando os dados do Censo EAD.BR (ABED, 2015) que retratam a EaD como uma modalidade educacional que está presente em muitas partes do território brasileiro, levando cursos de todos os níveis e áreas de conhecimento. Para isso, precisa estar integrada a inovação, sendo essa a infraestrutura tecnológica e de apoio ao aluno. Para Maftum e Campos (2008, p. 133) a "prática educativa a EaD se constitui como alternativa eficiente às amplas e diversificadas necessidades de qualificação de pessoas adultas". Com isso, ao utilizar os métodos PBL como ferramenta nos meios tecnológicos para desenvolver as potencialidades do aluno, vem sendo cada vez mais utilizadas nos 
meios educacionais EaD.

\section{COLETA E ANÁLISE DOS DADOS}

As Metodologias ativas como foi apresentada, traz o conceito alinhada a uma variedade de estratégias de ensino, entre elas a aprendizagem baseada em problemas, que na presente pesquisa é aplicada no curso de Pedagogia EaD em uma Instituição de Ensino Superior privada por meio do ambiente virtual de aprendizagem (AVA).

Com o intuito de analisar se as metodologias PBL são capazes de promover um processo de ensino e aprendizagem satisfatória em cursos a distância, é que no primeiro momento questionou se a utilização favorece a autonomia do educando?

Referente a tal questão $95 \%$ dos entrevistados afirmaram estar satisfeitos com a metodologia PBL em seu desenvolvimento social e educacional; seguidos de $5 \%$ que afirmam ter dificuldade de apresentar suas dúvidas e formar opiniões em grupo. Ainda assim, estes atribuíram ao método uma eficácia para auxiliá-los a superar essas limitações.

Sobre a PBL como ferramenta na EaD no auxilio da construção do conhecimento no indivíduo, Valente (2014, p. 147) reforça que

\footnotetext{
A EaD, ao utilizar recursos tecnológicos, apresenta características que podem contribuir para uma aprendizagem baseada na construção de conhecimento, já que as facilidades de interação via Internet permitem um tipo de educação que é muito difícil de ser realizado presencialmente. A EaD pode utilizar abordagens pedagógicas que exploram os verdadeiros potenciais que as TDICs oferecem, ao facilitar não somente o aprofundamento da interação professor-aprendiz, mas também entre aprendizes, o que propicia meios para uma educação dificilmente implantada em ações estritamente presenciais (VALENTE, 2014, p. 147).
}

Diante disso, a literatura evidencia que a educação contemporânea não comporta mais um modelo tradicional de educação. Para isso, Moran (2015), afirma que o ensino formal vem passando e necessitando ser mais híbrido e misturado. E essa transformação nos métodos de ensino pode levar tanto o aluno como a instituição a enfrentar as mudanças necessárias que estão cada vez mais presente no meio educacional e social em debaterem e ouvir as opiniões para assim as relações e a aprendizagem ocorrer de maneira sistêmica.

Para entender se a dificuldade que o acadêmico tem em se envolver e despertar, ter curiosidade, levando a tomar decisões individuais e coletivas, foi levantada a seguinte questão: como foi para o aluno auto gerenciar ou auto governar seu processo de e ensino e aprendizagem? Já que o professor não ensinaria mais de maneira tradicional. 
Seu papel é de mediar, levando os alunos a encontrarem sentido nos materiais e atividades disponíveis no grupo (MORAN, 2015).

Teve-se como respostas, $80 \%$ dos entrevistados afirmando que se sentiram seguros em dividir e encontrar soluções para os problemas em equipe, tendo como apoio o professor, $20 \%$ desses colocam que se sentem inseguros em tomar decisões somente pelo crivo dos colegas do grupo.

Para isso, se faz necessário analisar que a fundamentação teórica na pedagogia de Freire (2005, p. 78) defende uma educação como prática da liberdade "[...] não pode fundar-se numa compreensão dos homens como seres 'vazios' a quem o mundo 'enche' de conteúdos. Não pode ser a do depósito de conteúdos, mas a da problematização dos homens em suas relações com o mundo". Diante disso, evidencia que a metodologia PBL que tem o aluno como centro do processo de aprendizagem, e o professor o papel de pesquisar metodologias que desenvolvam nos mesmos as competências para a problematização, está de encontro com a fundamentação de Freire (2005).

Com intuito de mensurar se o PBL na EaD auxilia no processo de construção de conhecimento, levantou-se a seguinte questão. O protagonismo do PBL para o estudante em seu processo de aprendizagem possibilita o desenvolvimento de habilidades e competências indispensáveis para a construção de sua autonomia intelectual e social levando assim ao aprendizado satisfatório?

Deu-se como resultado 95\% dos entrevistados afirmando que o envolvimento do aluno em novas aprendizagens os prepara melhor para o futuro e nas cobranças sociais do processo que vivencia, preparando-se para o exercício profissional futuro; $5 \%$ relatam que mesmo o engajamento em relação a novas aprendizagens, são importantes, sentiram dificuldade na compreensão, na escolha e interesse nos conteúdos, para estes a presença e intervenção do professor na construção do conhecimento é condição essencial para ampliar suas possibilidades de exercitar a tomada de decisões em diferentes momentos.

De acordo com Pinto et al (2013, p. 3), "o protagonismo do estudante em seu processo de aprendizagem possibilita o desenvolvimento de habilidades e competências indispensáveis para a construção de sua autonomia intelectual e social". O trabalho em grupo toma destaque quando se fala em desenvolvimento de atividades que valoriza a convivência e a participação dos alunos, de forma autônoma, criativa, criando espaços de trabalho cooperativo, no qual todos os alunos são protagonistas, colaborando assim 
com a aprendizagem integral, individual e mútua.

Sardo (2007, p. 35) em relação ao envolvimento do aluno menciona que

Colocar o aluno diante de informações, problemas e objetos de conhecimento, utilizando as TIC como suporte a $\mathrm{EaD}$ não é suficiente para o envolver no processo de ensino-aprendizagem. Para que isso aconteça, faz-se necessário despertar nele uma inquietação/desafio pela aprendizagem, levando-o a criar procedimentos pessoais que lhe permitam organizar o próprio tempo para estudos e participação nas atividades, independente do horário ou local em que esteja.

Diante dos resultados aqui apresentados, percebe-se que as metodologias ativas aplicadas na EaD como uma alternativa para deslocar o foco da educação do ensinar para o que aprender (SARDO, 2007). Para tanto, é possível observar que a aplicação do PBL no AVA é um importante meio de potencializam a aprendizagem de maneira ativa, levando o aluno por meio de um problema buscar a resolução, a apresentação dos resultados e da autoavaliação e, por conseguinte ao desenvolvimento de suas potencialidades.

\section{CONSIDERAÇÕES FINAIS}

O ensino na modalidade a distância tem avançado muito, e com ele as novas tecnologias sendo sua grande alinhada nesse processo de crescimento. A presente pesquisa ao tratar do levantamento de dados bibliográficos e estudo de caso em um curso online, pode observar os pontos positivos da utilização da PBL como meio de aprendizagem dos alunos, como também, a levar uma flexibilidade, bem como, a remoção de barreiras espaciais entre os alunos e os meios sociais vivenciados por cada um, possibilitando assim que utilizassem o seus potenciais de interatividade da TDIC e colegas de estudos.

Os aspectos negativos, observados no levantamento de dados, estão nos relatos dos alunos quando mencionaram ter dificuldade e sentem falta da autoridade do professor em indicar, determinar e trazer as aulas práticas como meio de ensino e aprendizagem. Outro ponto é a timidez em fazer valer sua opinião no meio que está interagindo, levando assim a evasão de participantes.

Por fim, a análise alcançada é que ao trabalhar com a PBL é possível aumentar o tempo de estudo dos alunos, levando a uma participação prazerosa e construtiva por meio de aulas dinâmicas e motivadoras desenvolvendo habilidades interpessoais, de pesquisa em buscar juntos a solucionar problemas de modo ativo. 


\section{REFERÊNCIAS}

ABED - Associação Brasileira de Educação a Distância. Censo EAD.BR: Relatório Analítico da Aprendizagem a Distância no Brasil 2015. Curitiba: InterSaberes, 2016.Disponível em: . Acesso em: 08 maio 2018.

BRASIL. Decreto no 5.622, de 19 de dezembro de 2005. Disponível em: . Acesso em: 08 maio 2018.

DEWEY, John. Democracia e Educação: introdução à filosofia da educação.

3. ed. São Paulo: Companhia Editora Nacional, 1979.

FREIRE, P.. Pedagogia do oprimido. Rio de Janeiro: Paz e Terra. 2005.

PARK, Sung Hee. Impact of Problem-Based Learning (PBL) on teachers' beliefs regarding technology use. 2006. f171. Thesis (Doctoral in Philosophy) - Faculty of Purdue University, West Lafayette, 2006.

MAFTUM, Mariluci Alves; CAMPOS, João Batista. Capacitação pedagógica na modalidade de Educação a Distância: desafio para ativar processos de mudança na formação de profissionais de saúde. Cogitare Enfermagem, v. 13, n. 1, p.132-139, 2008. Disponível em: . Acesso em: 08 maio 2018.

MORAN, José Manuel. Mudando a educação com metodologias ativas.In: SOUZA, Carlos Alberto de; MORALES, Ofelia Elisa Torres (Org.). Convergências midiáticas, educação e cidadania: aproximações jovens. Ponta Grossa, PR: UEPG/PROEX, 2015. (Coleção Mídias Contemporâneas, v. 2). p. 15-33.Disponível em: . Acesso em: 08 maio 2018.

PARK, Sung Hee. Impact of problem-based learning (PBL) on teachers' beliefs regarding technology use. 2006. Thesis (Doctoral in Philosophy) - Faculty of Purdue University, West Lafayette, 2006.

PINTO, Antonio Sávio da Silva et al. O Laboratório de Metodologias Inovadoras e sua pesquisa sobre o uso de metodologias ativas pelos cursos de licenciatura do UNISAL, Lorena: estendendo o conhecimento para além da sala de aula. Revista Ciências da Educação,ano XV, v. 2, n. 29, p.67-79, dez. 2013. Disponível em: . Acesso em: 08 maio 2018. 
SARDO, Pedro Miguel Garcez. Aprendizagem baseada em problemas em reanimação cardiopulmonar no ambiente virtual de aprendizagem Moodle®. 2007. 226p. Dissertação (Mestrado em Enfermagem)—Universidade Federal de Santa Catarina, Florianópolis, 2007. Disponível em: . Acesso em: 08 maio 2018.

SOUZA e DOURADO. Aprendizagem Baseada em Problemas (ABP): Um Método de Aprendizagem Inovador para o Ensino Educativo S. C. Souza1* E L. Dourado Instituto Federal de Educação, Ciência e Tecnologia do Rio Grande de Norte - IFRN Universidade do Minho (Portugal) (2015) HOLOS, Ano 31, Vol. 5182.

VALENTE, José Armando. A comunicação e a educação baseada no uso das tecnologias de digitais de informação e comunicação. Revista Unifeso -Humanas e Sociais, v. 1, n. 1, p.141-166, 2014. Disponível em: . Acesso em: 08 maio 2018. 